\title{
A 3 year retrospective study of pregnancies complicated with placenta previa in a tertiary care centre
}

\author{
Vatsala Kamath, Aparna C. Aravind*, Nishita Shettian
}

Department of OBG, A.J. Institute of Medical Sciences and Research Centre, Kuntikana, Mangalore, Karnataka, India

Received: 10 December 2020

Revised: 24 December 2020

Accepted: 25 December 2020

\section{*Correspondence:}

Dr. Aparna C. Aravind,

E-mail: abuprids@gmail.com

Copyright: $\odot$ the author(s), publisher and licensee Medip Academy. This is an open-access article distributed under the terms of the Creative Commons Attribution Non-Commercial License, which permits unrestricted non-commercial use, distribution, and reproduction in any medium, provided the original work is properly cited.

\section{ABSTRACT}

Background: Placenta previa describes when a placenta is implanted partially or completely over the internal OS. About one third of the ante partum haemorrhage belongs to placenta previa. The incidence is increased beyond the age of 35 years, with high birth order pregnancies, prior caesarean deliveries and in multiple pregnancy. The aim of the study was to determine maternal and fetal outcome in pregnancies complicated with placenta previa.

Methods: A 3 year retrospective study done in OBG department of A. J. Institute of Medical Sciences, Mangalore from January 2017- January 2020. All pregnant women who are diagnosed with placenta previa during regular antenatal care (ANC) follow up, at or after admission and during caesarean delivery are included in the study. Data were collected from the hospital records.

Results: During the study period, there were 34 pregnant women with placenta previa. Maximum were in the age group of 31-35 years of age and 8.82 percentage were in the age group more than 35 years. Out of the study subjects, 76.5 percentage were multigravidas and 50 percentage were giving history of prior one caesarean section. 29.4 percentage of study subjects had true placenta previa and 85.2 percentage underwent elective caesarean section. There were significantly higher number of babies required neonatal intensive care unit (NICU) admissions.

Conclusions: An increase in the incidence of women with advanced maternal age, multiparity, prior caesarean deliveries contributes to a rise in the number of pregnancies complicated with placenta previa.

Keywords: Placenta previa, Antepartum haemorrhage, Caesarean hysterectomy, Postpartum haemorrhage

\section{INTRODUCTION}

Placenta previa describes when a placenta is implanted partially or completely over the lower uterine segment (over and adjacent to the internal os). ${ }^{1}$ The Latin previa means a going before - and in this sense, the placenta goes before the fetus into the birth canal.

About one third of the ante partum haemorrhage belongs to placenta previa. In $80 \%$ cases, it is found in multiparous women. The incidence is increased beyond the age of 35 years, with high birth order pregnancies, prior ceasearen deliveries and in multiple pregnancy. ${ }^{2}$
In a recent fetal imaging workshop sponsored by the National Institutes of Health (Dashe), the following classification was recommended: placenta previa-the internal os is covered partially or completely by placenta. In the past, these were further classified as either total or partial previa. Low-lying placenta-implantation in the lower uterine segment is such that the placental edge does not reach the internal os and remains outside a $2 \mathrm{~cm}$ wide perimeter around the os. A previously used term, marginal previa, described a placenta that was at the edge of the internal os but did not overlie it. 
Placenta praevia has been well documented to be associated with adverse maternal outcomes as well as neonatal outcomes. ${ }^{3}$ There were higher incidence of postpartum haemorrhage (PPH) and blood transfusion in women with placenta praevia compared to general population. ${ }^{4-6}$ Women with placenta praevia were more likely to deliver babies before 37 weeks with APGAR (appearance, pulse, grimace, activity, and respiration) score of less than 7. Studies also showed that there were higher admission to neonatal intensive care unit, still birth and death. ${ }^{7,8}$

Studies have reported $5 \%$ of obstetric hysterectomies were due to placenta praevia. ${ }^{4,9}$ The indication for emergency peripartum hysterectomy in recent years has changed from traditional uterine atony to abnormal placentation that has now become a more common indication due to greater number of pregnant women with previous caesarean scar.

The primary outcome of the present study was to determine maternal and fetal outcome in pregnancies with placenta previa.

\section{Aims and objectives}

To determine maternal and fetal outcome in pregnancies complicated with placenta previa.

\section{METHODS}

It is a 3 years retrospective study done in OBG department of A. J. Institute of Medical Sciences, Mangalore from January 2017- January 2020. Data was collected from the hospital records about all the patients with placenta previa who were admitted and underwent delivery during this time window.

\section{Inclusion criteria}

All pregnant women who were diagnosed with placenta previa during regular ANC follow up, at or after admission and during caesarean section.

\section{Exclusion criteria}

IUFD $<24$ weeks. Twin pregnancy.

Data collected included the following: age, parity, gestational age and clinical features at presentation, detailed history of current pregnancy and previous pregnancies, period of gestation at which placenta previa was diagnosed, route of delivery (vaginal or caesarean) duration of hospitalization, need for blood transfusion, peripartum hysterectomy, ICU admissions and for the new born - gestational age at delivery, APGAR score, birth weight, need for NICU admission.

Data entry was done in Microsoft office excel 2013 spread sheets and data was analysed using Statistical package for social sciences (SPPS) trial version 20.0.

\section{RESULTS}

During the study period, there were 34 pregnant women with placenta previa. Table 1 analysed the age distribution of women with placenta previa. Maximum were in the age group of 31-35 years of age.

Table 1: Age distribution of women with placenta previa.

\begin{tabular}{|lll|}
\hline Age (in years) & Number & Percentage \\
\hline $\mathbf{2 0}$ & 1 & 2.94 \\
\hline $\mathbf{2 1 - 2 5}$ & 11 & 32.35 \\
\hline $\mathbf{2 6 - 3 0}$ & 7 & 20.59 \\
\hline $\mathbf{3 1 - 3 5}$ & 12 & 35.29 \\
\hline $\mathbf{3 5}$ & 3 & 8.82 \\
\hline
\end{tabular}

Results are expressed as number, incidence (\%)

Table 2: Risk factors associated with placenta previa.

\begin{tabular}{|lll|}
\hline \multicolumn{2}{|l|}{ Number } & Percentage \\
\hline Age $>$ 35 years & 3 & 8.82 \\
\hline Gravida & & \\
\hline Primigravida & 8 & 23.5 \\
\hline Multigravida & 26 & 76.5 \\
\hline H/o previous cesearean section \\
\hline$>1$ & 17 & 50 \\
\hline$\geq 2$ & 2 & 5.88 \\
\hline Prior d and c & 3 & 8.82 \\
\hline
\end{tabular}

Table 3: Obstetric outcome in women with placenta previa.

\begin{tabular}{|c|c|c|}
\hline & $\begin{array}{l}\text { Number } \\
(n=34)\end{array}$ & Percentage \\
\hline \multicolumn{3}{|c|}{ Types of placenta previa } \\
\hline True placenta previa & 10 & 29.4 \\
\hline Low lying placenta & 24 & 70.5 \\
\hline \multicolumn{3}{|c|}{ Types of caesarean section } \\
\hline Lower segment & 34 & 100 \\
\hline Classical & - & - \\
\hline \multicolumn{3}{|c|}{ Caesarean section percentage } \\
\hline Elective & 29 & 85.2 \\
\hline Emergency & 5 & 14.7 \\
\hline Estimated blood loss & $889 \pm 129.9$ & \\
\hline H/o blood transfusion & 4 & 11.76 \\
\hline \multicolumn{3}{|l|}{ Intra operative } \\
\hline Placenta accreta & 1 & 2.94 \\
\hline $\begin{array}{l}\text { Peripartum } \\
\text { hysterectomy }\end{array}$ & - & - \\
\hline Maternal mortality & - & - \\
\hline
\end{tabular}

Results are expressed as number, incidence $(\%)$, mean \pm SD

Table 2 shows the risk factors associated with placenta previa and found out 8.82 percentage were in the age group more than 35 years and 76.5 percentage of the study subjects were multigravidas. 50 percentage of the study 
subjects were giving history of prior one caesarean section and 8.82 percentage had curettage performed on them.

Table 4: Neonatal outcome in placenta previa.

\begin{tabular}{|c|c|c|}
\hline & Number $(n=34)$ & Percentage \\
\hline \multicolumn{3}{|c|}{ Gestational age at delivery } \\
\hline 32-34 weeks & 3 & 8.82 \\
\hline $34^{+1}-36$ weeks & 8 & 23.52 \\
\hline $36^{+1}-38$ weeks & 23 & 67.64 \\
\hline \multicolumn{3}{|l|}{ Birth weight } \\
\hline$<1.4 \mathrm{~kg}$ & - & - \\
\hline $1.5-2.4 \mathrm{~kg}$ & 8 & 23.53 \\
\hline $2.5-3.4 \mathrm{~kg}$ & 21 & 61.76 \\
\hline$>3.5 \mathrm{~kg}$ & 5 & 14.71 \\
\hline $\begin{array}{l}\text { APGAR score }<7 \text { in } \\
5 \mathrm{~min}\end{array}$ & 7 & 20.59 \\
\hline NICU admission & 19 & 55.88 \\
\hline
\end{tabular}

Results are expressed as number, percentage

Table 3 shows the comparison of obstetric outcome in women with placenta previa. 29.4 percentage of study subjects had true placenta previa and 85.2 percentage underwent elective caesarean section. 11.76 percentage in the study group had history of blood transfusion postoperatively. Out of the 34 study subjects, one had placenta accreta.

Table 4 shows the comparison of neonatal outcomes in placenta previa. Gestational age at delivery was more in 36 to 38 weeks of gestation. The APGAR score less than 7 at 5 minutes were 20.59 percentage and there were significantly higher number of babies required NICU admissions.

\section{DISCUSSION}

Placenta previa is a serious obstetric issue and should be managed by experienced teams. The associated morbidities include hemorrhage (antepartum, intrapartum, and postpartum), abnormal placental adherence, need for Caesarean hysterectomy and blood transfusion, septicemia, and thrombophlebitis. ${ }^{10}$ The potential for emotional distress on the part of the woman involved, arising from episodes of heavy vaginal bleeding, the need for repeated hospitalizations, and concern for her baby's welfare, cannot be trivialized. The more we can do to reduce the incidence of placenta previa, and avoid these consequences, the better. ${ }^{11}$

About 34 cases were reported during the study period and maximum were in the age group of 31-35 years of age.

According to RCOG, the risk factors include previous placenta previa (adjusted odds ratio (OR) 9.7), previous caesarean sections (relative risk (RR) 2.6, 95\% confidence interval (CI) 2.3-3.0 with a background rate of $0.5 \%$ ), one previous caesarean section OR 2.2 (95\% CI 1.4-3.4 with a background rate of $1 \%$ ), two previous caesarean sections
OR 4.1 (95\% CI 1.9-8.8), Three previous caesarean sections OR 22.4 (95\% CI 6.4-78.3). ${ }^{12}$

In the present study, 76.5 percentage of the study subjects were multigravidas. 50 percentage of the study subjects were giving history of prior one caesarean section and 8.82 percentage had curettage performed on them.

In population based retrospective cohort study in Nova Scotia, Canada from 1988-1995, 308 cases of placenta previa were identified. Maternal complications included postpartum bleeding (RR-1.86), hysterectomy (RR 33.26), blood transfusion (RR-10.05), and septicaemia (RR5.55). Risk factor for hysterectomy in women with placenta previa included presence of placenta accrete and previous caesarean. ${ }^{13}$ In the present study 29.4 percentage of study subjects had true placenta previa and 85.2 percentage underwent elective caesarean section. 11.76 percentage in the study group had history of blood transfusion postoperatively. Out of the 34 study subjects, one had placenta accreta.

Neonatal morbidity in the present study was significant. Gestational age at delivery was more in 36 to 38 weeks of gestation. The APGAR score less than 7 at 5 minutes were 20.59 percentage and there were significantly higher number of babies required NICU admissions.

This study has some limitations. First, as the major limitation, the number of the study group is too small and subjects with twin pregnancy, intrauterine fetal death were excluded. However, the present study has some interesting results regarding the maternal and neonatal outcomes.

\section{CONCLUSION}

An increase in the incidence of women with advanced maternal age, multiparity, prior caesarean deliveries contributes to a rise in the number of pregnancies complicated with placenta previa. Timely delivery in pregnancies complicated with placenta previa can reduce further maternal and perinatal complications.

\section{Funding: No funding sources \\ Conflict of interest: None declared}

Ethical approval: The study was approved by the Institutional Ethics Committee

\section{REFERENCES}

1. Cunningham, Leveno, Bloom, Oashe, Hoffman, Gasey et al. Williams Obsttrics. 25th edition.

2. Azurah AGN, Zainol ZW, Lim PS, Shafiee MN, Kampan N, Mohsin WS. Factors Associated with Placenta Praevia in Primigravidas and Its Pregnancy Outcome. The Scientific World Journal. 2014;2014.

3. Olive EC, Roberts CL, Algert CS, and Morris JM. Placenta praevia: maternal morbidity and place of birth.Australian and New Zealand Journal of Obstetrics and Gynaecology. 2005;45:499-504. 
4. Takayama T, Minakami H, Koike T, Watanabe T, Sato I. Risks associated with cesarean sections in women with placentaprevia. Journal of Obstetrics and Gynaecology Research. 1997;23(4):375-79.

5. Tuzovic L. Complete versus incomplete placenta previa and obstetric outcome. International Journal of Gynecology and Obstetrics. 2006;93(2):110-17.

6. Onwere C, Gurol-Urganci I, Cromwell DA, Mahmood TA, Templeton A, van der Meulen JH. Maternal morbidity associated with placenta praevia among women who had elective caesarean section. European Journal of Obstetrics and Gynecology and Reproductive Biology. 2011;159(1):62-66.

7. Schneiderman M, Balayla J. A comparative study of neonatal outcomes in placenta previa versus caesarean for other indication at term.Journal of Maternal-Fetal and Neonatal Medicine.2013;26(11):1121-27.

8. T. Rosenberg, G. Pariente, R. Sergienko, A. Wiznitzer, and E. Sheiner.Critical analysis of risk factors and outcome of placentaprevia.Archivesof Gynecologyand Obstetrics. 2011;284(1):47-51.
9. J. M. G. Crane, M. C. van den Hof, L. Dodds, B. A. Armson, and R. Liston.Maternal complications with placenta previa.The American Journal of Perinatology. 2000;17(2):101-105.

10. Oyelese Y. Placenta previa: the evolving role of ultrasound. Ultrasound Obstr Gynecol. 2009;34(2):123-6.

11. Timothy Rowe, MB BS, FRCSC. Placenta Previa. AUGUST JOGC AOÛT. 2014

12. Gilliam M, Rosenberg D, Davis F. The likelihood of placenta previa with greater number of caesarean delivery and higher parity. Obstet Gynecol. 2002;99(6):976-80.

Cite this article as: Kamath $\mathrm{V}$, Aravind AC, Shettian N. A 3 year retrospective study of pregnancies complicated with placenta previa in a tertiary care centre. Int $\mathbf{J}$ Reprod Contracept Obstet Gynecol 2021;10:520-3. 